\title{
Camponês e Agricultor Familiar: mesmos sujeitos?
}

\author{
Peasantry and Family Farmer: same Subjects? \\ Campesino y Agricultor Familiar: mismos sujetos?

\begin{abstract}
Rosaly Stange Azevedo ${ }^{1}$ André Filipe Pereira Reid dos Santos ${ }^{2}$
\end{abstract}

Recebido em 04/02/2016. Aceito em 23/02/2017.

\begin{abstract}
Resumo
O trabalho pretende analisar a confusão existente acerca dos conceitos de agricultura familiar e campesinato, mais especificamente responder se são categorias que abarcam os mesmos sujeitos ou, ao revés, sujeitos distintos. Para tanto, apresenta pontos centrais dos dois paradigmas sobre os quais se desenvolve o debate acerca da complexidade da chamada questão agrária, os quais possuem visões antagônicas: o paradigma da Questão Agrária, que vê o agricultor familiar e o camponês como mesmos sujeitos e o paradigma do Capitalismo Agrário, que entende que o agricultor familiar é o camponês inserido no mercado. A hipótese que será apresentada neste estudo segue as diretrizes do paradigma da Questão Agrária, de tradição marxista. Assim, o desafio a que nos propomos é demonstrar que agricultura familiar e campesinato são sinônimos, tendência pela reafirmação do prestígio das categorias "camponês" e "campesinato", de forma a valorizar o agricultor que trabalha com sua família na terra, de onde retira o sustento de sua família. O método utilizado é o dialético.
\end{abstract}

Palavras-Chave: Agricultura familiar; Campesinato; Questão agrária.

\begin{abstract}
This article aims to analyze the existing confusion between the concepts of family farm and peasantry, more specifically to answer if they are categories that include the same subjects or different ones. In this sense, it shows the key points of two paradigms, with opposing views, over which the debate on the complexity of the agrarian question is developed: the paradigm of the agrarian question, which sees the family farmers and the peasant as the same subjects, and the paradigm of the agrarian capitalism, which sees the family farmer as the peasant in the work market. The hypothesis that will be presented in this study follows the same guidelines of the agrarian question paradigm, from a Marxian tradition. Therefore, the challenge that we proposed was to show that family farm and peasantry are synonyms, which tends to reaffirm the prestige of the categories "peasant" and "peasantry" in order to value the farmers who work with their families on the land, where they find the sustenance for their families. The method used is the dialectical.
\end{abstract}

Key Words: Family farm. Peasantry. Agrarian question.

\section{Resumen}

El trabajo pretende analizar la confusión existente acerca de los conceptos de agricultura familiar y campesina, más específicamente responder si son categorías que abarcan los mismos sujetos o, al revés, sujetos distintos. Para ello, presenta puntos centrales de los dos paradigmas sobre los que se desarrolla el debate acerca de la complejidad de la llamada Cuestión Agraria, los cuales poseen visiones antagónicas: el paradigma de la Cuestión Agraria, que ve al agricultor familiar y al campesino como mismos sujetos y el paradigma del Capitalismo Agrario, que entiende que el agricultor familiar es el campesino insertado en el mercado. La hipótesis que se presentará en este estudio sigue las directrices del paradigma de la Cuestión Agraria, de tradición marxista. Así, el desafío a que nos proponemos es demostrar que la

Geografia (Londrina) v. 26. no. 2. p. $58-77$, jul/dez, 2017. 
agricultura familiar y campesina son sinónimos, tendencia por la reafirmación del prestigio de las categorías "campesino" y "campesinado", para valorar al agricultor que trabaja con su familia en la tierra, I agricultor que trabaja con su familia en la tierra, de donde retira el sustento de su familia. El método utilizado es el dialéctico.

Palabras Clave: Agricultura familiar. Campesinado. Cuestión agraria.

\section{INTRODUÇÃO}

O objetivo inicial deste artigo é responder ao seguinte questionamento: camponês e agricultor familiar são os mesmos sujeitos, ou tais conceitos designam identidades distintas, indivíduos com objetivos e anseios divergentes? A dificuldade teórica de avançar uma hipótese construtiva na análise das particularidades dos conceitos de campesinato e agricultura familiar demanda a observância de passos subsequentes, que serão articulados neste artigo.

Inicialmente serão analisados alguns pontos centrais dos dois paradigmas sobre os quais se desenvolve o debate acerca da complexidade da chamada questão agrária: 1) o paradigma da Questão Agrária, que defende o protagonismo do campesinato nas lutas pela terra e prevê a superação do sistema capitalista e; 2) o paradigma do Capitalismo Agrário, o qual entende que os problemas agrários decorrentes do capitalismo podem ser solucionados e superados internamente ao sistema. Em seguida, procura-se apresentar o conceito de campesinato, com todas as suas contradições, uma categoria heterogênea, com vasta gama de características, que vão do tradicional ao moderno, dependendo do maior ou menor grau de integração aos mercados. Em razão de seu modo de vida peculiar e de sua organização em unidades comunitárias, sua identidade é construída a partir de um padrão geral distinto no mundo social, fundado na centralidade do trabalho da coletividade familiar.

A hipótese que será apresentada neste estudo segue as diretrizes do paradigma da Questão Agrária, de tradição marxista. O método utilizado é o dialético. Assim, o desafio a que nos propomos é demonstrar que agricultura familiar e campesinato são sinônimos, análise alinhada à tendência pela reafirmação do prestígio das categorias "camponês" e "campesinato", de forma a valorizar o agricultor que trabalha com sua família na terra, de onde retira o sustento de sua família.

Estudar os problemas que se produzem no espaço rural requer um levantamento das teorias que servem para compreender o modo de vida do camponês e as pressões estruturais exercidas sobre ele. $\mathrm{O}$ trabalho realizado no campo tem características próprias e, em geral, os trabalhadores do campo são analisados pela sociologia e geografia como sendo camponeses. Mas a expressão "camponês" não é apenas uma mera nomenclatura, como será visto a seguir. 


\section{PARADIGMAS DA QUESTÃO AGRÁRIA E DO CAPITALISMO AGRÁRIO}

A ausência de perspectivas de futuro do campesinato em países periféricos como o Brasil guarda direta relação com a obsolescência dos antigos projetos políticos, pautados em análises tradicionais, os quais apostaram historicamente em uma agricultura baseada em latifúndios exportadores e monocultores. Assim, a análise dos paradigmas subjacentes às categorias "campesinato" e "agricultura familiar" não tem apenas repercussões teóricas. Antes, trata do reconhecimento do protagonismo do campesinato nas lutas pela terra e possibilita nortear e traçar perspectivas políticas, pautadas na superação do sistema capitalista, ou na noção de que os problemas agrários decorrentes do capitalismo devam ser solucionados internamente ao sistema. Em poucas palavras, o debate sobre a questão agrária tem, por pano de fundo, a escolha pela superação ou pela manutenção do capitalismo.

Um importante desafio para o enfrentamento de reflexões acerca das diferentes visões da questão agrária passa, precisamente, pelo conceito de paradigma. Embora não seja objeto deste trabalho, é importante passar pelo tema, ainda que de forma sucinta. A tarefa não é simples, dado que o termo paradigma não possui conotação precisa. Sua origem remonta a Teoria das Ideias de Platão, na Grécia (paradeigma) e seu significado aproxima-se aos conceitos de modelo e exemplo, remetendo às formas e às ideias. Thomas Samuel Kuhn retomou o conceito, na década de 1960, em seu estudo $A$ Estrutura das Revoluções Científicas (ERC), atribuindo múltiplos significados ao termo. Não sendo este o objeto de nosso estudo, adotamos o conceito kuhniano de paradigma como "um eixo de maior abrangência, que inclui um conjunto de elementos compartilhados pela comunidade científica, constituído, especialmente, por teorias, métodos, metodologias e atitudes que proporcionam aos seus membros uma visão de mundo" (CAMPOS, 2012, p. 47). A rigor, o presente estudo busca o aperfeiçoamento das questões relacionadas à temática agrária, separando as peças de dois conjuntos distintos de quebra-cabeças, no que Kuhn denominou "operações de limpeza", ou seja, "trabalho de depuração das persistentes inconsistências do paradigma" (MENDONÇA, 2012).

A resposta a que nos propomos, isso é, se o camponês e o agricultor familiar são o mesmo do mesmo, ou seja, mesmos sujeitos, se dará a partir da percepção de que a questão agrária se encontra em uma etapa científica específica, a fase de desenvolvimento denominada por Kuhn (2007) como ciência normal. Isso porque existe, na comunidade científica, uma aceitação da existência de duas matrizes disciplinares antagônicas sobre o problema agrário, contendo práticas de construção do conhecimento científico em comum (KUHN, 2007, p. 221), sobre as quais desenvolveremos nossa tese. Campos (2012 p. 47) nos lembra que não é necessário que o paradigma ofereça respostas de forma imediata para que o conjunto de questões possa ser classificado como um "quebra-cabeças" a ser 
resolvido. Ao optar por uma exposição em forma de duas concepções paradigmáticas, metáfora da forma, resoluções pré-moldadas, corre-se o risco de descartar concepções e debates tidos como peças não essenciais, estranhas à montagem do "quebra-cabeça" dos paradigmas apresentados, em um processo artificial de universalização da ciência. Optamos por caminhar à beira do precipício, para caminhar, pois "mesmo coibindo o pesquisador a uma visão de mundo específica, o comprometimento com um paradigma é condição proeminente, pois favorece o avanço e o desenvolvimento das pesquisas" (CAMPOS, 2012 p. 49).

O "corte vertical" (CAMPOS, 2012 p. 49) foi feito. O desenho de nosso "quebracabeça" parte do pressuposto de que existe uma ciência dita normal a respeito da questão agrária. A montagem de nosso "jogo", ou seja, a construção do presente texto segue o método proposto por Felício (2011), o qual possibilita compreender as teorias que compõem os dois paradigmas citados no título de seu estudo: o paradigma da Questão Agrária e o paradigma do Capitalismo Agrário. O procedimento sistemático percorrido por Felício foi adotado, neste primeiro tópico, em razão de sua clareza e didática, possibilitando a descrição e a explicação dos compromissos ideológicos subjacentes às duas principais linhas investigativas apresentadas. Os paradigmas da Questão Agrária e do Capitalismo Agrário são as duas lentes (SHANIN, 1983, p. 194) pelas quais se interpretam temas como o acesso à terra; a expansão do capitalismo no campo e o futuro do campesinato. Ênfases distintas para os mesmos problemas, pois "enquanto o paradigma da Questão Agrária denuncia a violência da exclusão e da expropriação, o paradigma do Capitalismo Agrário apenas constata" (FRNANDES, 2007, p. 79). Contudo, no que concerne ao prognóstico, a diferença é abissal. Enquanto que para o paradigma da Questão Agrária, a solução está na luta de classes e na destruição do capital, para o paradigma do Capitalismo Agrário a integração é a resposta para todos os problemas do homem do campo (FERNANDES, 2007, p. 79). Na disputa, mercado renegado versus mercado venerado.

A temática envolvendo a distribuição fundiária, no paradigma da Questão Agrária, entende que as abissais desigualdades, raízes de todos os conflitos, são estruturais e decorrentes do desenvolvimento do capitalismo no campo, só podendo ser superadas quando esse mesmo capitalismo for substituído por outra sociedade, não-capitalista. A partir do método dialético, compreendem-se as contradições do sistema e os processos históricos mediante a luta de classes. O trabalhador camponês é visto como um agente ativo na luta pela reforma agrária e, o campo, como espaço de resistência ao sistema capitalista, que se (re)cria, em uma elevada posição de protagonismo na superação do capital. Já na visão dos teóricos do Capitalismo Agrário, os problemas que giram em torno do tema agrário não são estruturais, como no paradigma anterior, mas conjunturais, pois decorrem do capitalismo e devem ser resolvidos pela lógica interna ao sistema. O camponês é (re)criado pelo próprio 
capital, em sua lógica interna (FELÍCIO, 2011, p. 5-9). As principais linhas de argumentação partem da perspectiva de que o futuro do campesinato depende de sua integração ao sistema capitalista, por meio da submissão aos imperativos de mercado. Para os estudiosos dessa corrente, não há a chamada "questão agrária" no capitalismo.

\section{O paradigma da Questão Agrária}

As origens do debate agrário remontam a corrente de pensamento denominada marxismo agrário, a qual tem grande influência de três importantes autores clássicos: Marx, Lênin e Kautsky. A avaliação das estruturas sociais formadas pelos camponeses, nas obras desses três pensadores, deve ser analisada de acordo com o momento histórico em que viveram. Os pontos convergentes entre os pensadores são: foram contemporâneos e viveram no inquieto período entre o século $\mathrm{XIX}$ e início do século $\mathrm{XX}$, em que a produção capitalista consolidava-se. Os três autores acreditavam em uma radical transformação da sociedade, mediante a revolução armada, liderada pela classe proletária (BORSATTO; CARMO, 2013).

Os estudos de Marx não abordaram os pontos nucleares da questão agrária: a produção em bases familiares, suas tendências e sua importância no desenvolvimento do capitalismo. Especificamente acerca do tema campesinato, é possível perceber, nos escritos de Marx, uma visão política pessimista, como lembra Abramovay (2012, p. 32), a qual deve ser compreendida considerando-se as lutas políticas da época. O campo, na passagem do século XIX para o século XX, na Europa, era local de instabilidades sociais e econômicas. Os camponeses perdiam suas terras ou eram substituídos pelas máquinas, em razão da contínua política de expulsão da população rural. Seu destino era as manufaturas urbanas e os camponeses que ficavam no campo eram obrigados a se subordinarem às regras do mercado de trabalho e a adquirirem os meios necessários à sua subsistência, não mais pelo seu próprio trabalho na lida da terra, mas no mercado. Marx, em suas observações, percebe que o número de camponeses regride, assim como sua condição de vida. Com a liberação de parte da população rural, em razão dos processos de industrialização do campo, o camponês precisa buscar seu sustento, "deixado ao léu tem de adquirir de seu novo senhor, o capitalista industrial, e sob a forma de salário, o valor desses meios alimentares" (MARX, 2013, p. 816). Para o autor, a expropriação e a expulsão de uma parte da população rural possui um efeito duplamente positivo ao capital, pois não apenas amplia a oferta de trabalhadores para o capital industrial, como também fomenta o mercado interno, mediante - crescimento da procura de produtos anteriormente produzidos pelos próprios trabalhadores.

No pensamento de $\operatorname{Marx}$ (2011, p. 53-54), os camponeses não teriam o protagonismo no seu projeto socialista. Muito embora integrassem uma grande massa de 
trabalhadores que viviam em condições semelhantes, o isolamento, a ausência de divisão no trabalho e a pobreza, características do modo de produção campesino, acrescidos da dificuldade de comunicação, não permitiam o desenvolvimento de relações políticas de contestação. Ele chega a dizer que os camponeses são comparáveis a um saco de batatas: "A grande massa da nação francesa é, assim, formada pela simples adição de grandezas homólogas, da mesma maneira que batatas em um saco constituem um saco de batatas" (MARX, 2011, p. 54). Sua observação sobre os novos avanços na mecanização, na nutrição vegetal e na química agrícola, o levavam a acreditar que a grande unidade de produção capitalista evoluiria e seria hegemônica com o capitalismo. As vantagens da produção em grande escala seriam um fenômeno positivo e natural, necessário na passagem da organização capitalista para a organização socialista (BAIARDI; ALENCAR, 2014).

Kautsky foi o primeiro a formular uma teoria detalhada acerca da lógica do Capitalismo Agrário (CARNEIRO, 2009, p. 59). O prognóstico de Kautsky era que, com o advento do capitalismo e a industrialização no campo, a pequena propriedade desapareceria, dando lugar à grande propriedade agrícola, tecnicamente superior. A absorção das pequenas propriedades por parte das grandes era um fenômeno desejável, pois aceleraria o processo de expansão do socialismo no campo. As propriedades rurais com grandes áreas a serem cultivadas seriam mais apropriadas ao desenvolvimento do capitalismo, em razão de sua superioridade técnica em relação às pequenas propriedades. Assim, a "industrialização da agricultura" seria um objetivo a ser perseguido (KAUTSKY, 1980, p. 138-139).

O livro O Desenvolvimento do Capitalismo na Rússia, publicado em 1899, é mais uma obra clássica da teoria agrária, de autoria de Vladimir llitch Lênin. Nesse estudo, Lênin descreve o processo de formação do mercado interno para o capitalismo russo e apresenta suas críticas aos ideólogos populistas, os quais repeliam o capitalismo na Rússia por considerarem-no uma regressão; consideravam o campesinato da comunidade como algo superior, negando suas contradições, e rejeitavam a interconexão entre os intelectuais, as instituições político-jurídicas da Rússia e as ambições e interesses de classes dominantes (NETTO, 1985, p. X-XI).

Engels (1981, p. 63) apregoava o perecimento do pequeno camponês: "o pequeno camponês, como tudo que seja resquício de um modo de produção caduco, está condenado irremediavelmente a perecer. O pequeno lavrador é um futuro proletário". Para ele, o que impede o camponês de dar ouvidos à propaganda socialista é o "o instinto de propriedade que está em seu sangue". Como afirma Paulino (2012, p. 52), não se pode simplesmente dizer que Lênin e Kautsky incorreram em equívoco em seus prognósticos em relação ao futuro do pequeno produtor rural. Em verdade, suas ideias são fruto de uma "concepção linear do processo histórico, que pressupunha etapas a serem cumpridas para se chegar ao 
socialismo". As teorias de Lênin e Kautsky são bastante próximas, muito embora as ênfases tenham sido diferentes.

A obra do economista agrário russo Alexander Vasilevich Chayanov é seminal ao paradigma da Questão Agrária (FELÍCIO, 2011) e essencial nas reflexões sobre a lógica constitutiva e a resistência do campesinato, muito embora não seja compreendida como de influência marxista. Baiardi e Alencar (2015), ao analisar a capacidade de adaptação do campesinato, registraram que, no Brasil, a divulgação acadêmica do pensamento de Chayanov teve início a partir da segunda metade da década de 70 do século $\mathrm{XX}$, com o arrefecimento político da Ditadura Militar, no meio de um forte debate entre duas correntes de pensamento que buscavam a modernização agrária russa: a marxista e a populista. Aquela tentava aplicar as leis do materialismo histórico e o projeto de socialização das terras à lógica do campo, e esta, considerada pelos bolcheviques como de índole pequenoburguesa, propunha a queda do regime tzarista e a entrega das terras dos latifúndios para os agricultores familiares. Muito embora se autoproclamassem socialistas, os populistas, na ótica dos bolcheviques, eram utópicos, por se oporem ao pensamento marxista e defenderem que a revolução partiria do campesinato e não do proletariado.

Chayanov, profundo conhecedor da realidade camponesa, desenvolveu estudos em direção inversa às teorias agrárias de sua época, a partir de 1911, sobre questões centrais à organização produtiva camponesa, reconhecendo-a como uma unidade econômica com leis e fundamentos próprios. Ele não busca antever o destino da unidade econômica camponesa, mas compreendê-la a partir de um ponto de vista organizacional, a morfologia de seu aparato produtivo, os mecanismos de circulação de mercadorias produzidas internamente e suas reações aos fatores externos (CHAYANOV, 1974, p. 36). A sua teoria parte do pressuposto de que os limites máximo e mínimo do volume da atividade econômica da unidade de exploração doméstica são definidos pela composição familiar. Assim, a quantidade de trabalho é determinada pelas necessidades básicas familiares. O nível de bem-estar de todos os trabalhadores campesinos é medido pelo consumo de energia necessário ao atingimento de seus fins. É a relação entre o alcance das necessidades de consumo da família e a dificuldade do trabalho que estabelece o grau de exploração de seu trabalho (CHAYANOV, 1974, p. 84). O trabalhador da unidade agrária familiar camponesa define, ele mesmo, a intensidade de seu trabalho, a quantidade de horas trabalhadas, a medida de retorno de seu esforço, em uma auto-sujeição a que Chayanov chama do regime de autoexploração. Ao indicar as estratégias pelas quais os camponeses alcançam o equilíbrio entre trabalho e consumo familiar, Chayanov acaba por dar importantes indicativos para se compreender como as culturas que apresentam as menores taxas de retorno financeiro estão, em geral, no âmbito do domínio da unidade agrária familiar, dentre os quais: os meios de produção, muitas vezes, insuficientes para a escala de produção exigida 
pelas culturas consideradas mais nobres; a não preparação financeiramente para suportar os riscos peculiares às atividades mais rentáveis; a não propriedade dos meios para iniciar as culturas tidas como mais lucrativas (PAULINO, 2012, p. 61-63).

Na ótica de Rosa Luxemburg (1985), o campesinato, como relação de natureza précapitalista, é essencial à lógica do capitalismo, que se apropria tanto dos lucros gerados com o trabalho do agricultor familiar, quanto do trabalhador proletário. A lógica do capitalismo, para a citada autora, é a destruição do campesinato: "o capitalismo combate e suprime, onde pode, a economia natural, a produção de subsistência e a forma combinada da agricultura com o artesanato" (1985, p. 275). O campesinato, enquanto relação nãocapitalista, seria um impedimento lógico à expansão do capital e, por essa razão, tendente à aniquilação, pois "o capital esquadrinha o mundo inteiro, procura obter meios de produção em qualquer lugar e os tira e os adquire de todas as culturas dos mais diversos níveis, bem como de qualquer forma social" (LUXEMBURG, 1985, p. 245-246).

Segundo a autora em referência, os processos de acumulação do capital necessitam e dependem de elementos exteriores à sua lógica interna, dada a necessidade de manutenção do que chama de "mercados externos" ou "terceiras pessoas". Diante de uma crise de realização, o capital deve, necessariamente, buscar uma espécie de complementação externa ao seu próprio sistema, reserva cujo caráter possua uma dimensão espacial. Isso explicaria a contradição histórica de os antigos países capitalistas, serem ao mesmo tempo, mercados imprescindíveis uns aos outros e concorrentes em suas relações com os países não-capitalistas (SANTOS, 2010). Dessa forma, tais "reservas" territoriais "não-capitalistas", como são as relações camponesas de produção, estariam na estrutura do processo crítico de reprodução e sua aniquilação implicaria o fim do próprio capitalismo. A autora não vê as relações pré-capitalistas como "resíduos" ou ilhas de resistência, mas como parte articulada e necessária à lógica do capitalismo, pois o capital depende da existência concomitante de territórios não-capitalistas, pois, se a acumulação ocorre tanto nas formas de produção capitalista e não-capitalista, "então o capital encontrará como se apropriar tanto da mais-valia gerada com o assalariamento, quanto da renda fundiária propiciada com o trabalho familiar camponês" (FELÍCIO, 2011, p. 45).

Shanin (1983, p. 275-279) percebe o campesinato como um grupo que, apesar de constituir a maioria da população mundial, possui características estranhas aos conceitos gerais de sociedade contemporânea. Sua autonomia decorre de uma forte autossuficiência e da capacidade de resistência às pressões e às crises do mercado. Compreende o camponês como um sujeito protagonista da história e sua existência põe em evidência os problemas estruturais da Questão Agrária.

Na teoria de Bartra (2007, p. 86), o capitalismo vem impondo um reino uniforme, no qual o campesinato constitui uma anomalia. Para ele, enquanto a indústria tende para a 
especialização e à monotonia tecnológica, o campo é lugar onde a heterogeneidade impera: uma variedade de climas, paisagens e solos, que acaba por produzir uma variedade de atividades produtivas, pluralidade de sociedades e culturas. Bartra (2007, p. 87) percebe que o capital, desde sempre, busca o domínio da agricultura para transformá-la em uma indústria, mediante a substituição da renda da terra pela renda da vida, a partir do desenvolvimento da biotecnologia e do controle genético.

Os conceitos tomados pelos autores incluídos no paradigma da Questão Agrária não apenas permitem compreender as perspectivas, mas também, e principalmente, visualizar o marco político definido, a partir do qual emergem as interpretações que tornam possível o estabelecimento de novos significados na histórica luta pela terra de trabalho, pela liberdade e pelo reconhecimento do campesinato e seu papel perante o domínio asfixiante do capital. Em verdade, a importância da temática extrapola as fronteiras da produção agrícola e produz benefícios a toda a sociedade. Eis o fundamento do paradigma: um regime fundiário centrado no reconhecimento e valorização da classe camponesa, em que a partilha de terras é instrumento de democratização e distribuição de riqueza, em oposição à opção pelo modelo agroexportador e monocultor.

Ploeg (2008, p. 39) apresenta diferenças na estrutura produtiva entre a agricultura camponesa e a agricultura capitalista. A agricultura camponesa é constituída por processos históricos, dinâmicos, desenvolvidos em direções distintas da agricultura capitalista. O modelo de agricultura não camponesa segue o antigo modelo do Império, por haver uma centralização de uma cúpula que submete atividades produtivas e distributivas, interligadas entre si. Ainda para o citado autor (2008, p. 137), o fato de a agricultura camponesa comercializar sua produção no mercado não significa que o campesinato seja orientado pelas regras do capital, pois a oferta da produção agrícola ocorre, mesmo que o resultado do negócio não seja propriamente positivo.

Os estudos de Sabourin (2011) têm como temática central a teoria da reciprocidade, cujos elementos próprios seriam quatro: a) a noção de que o princípio de reciprocidade não está restrito a uma relação de dádiva e contra dádiva entre iguais, sendo, antes, uma categoria econômica distinta e oposta da troca mercantil; b) a reciprocidade pode assumir formas variadas: positivas (oferendas, partilhas, prestações totais) e negativas (a dos ciclos de vingança). Em sua concepção, o ideal de reciprocidade pode representar um motor do desenvolvimento de produção de excedentes tão transformador como é o da lógica da troca capitalista, ou seja, que objetiva o lucro, com a diferença de que as relações de reciprocidade possibilitam modos de regulação justos, sendo possível a limitação dos excessos, da mesma forma como existe a regulação dos excessos da livre concorrência e livre mercado. 


\section{O paradigma do Capitalismo Agrário}

Os autores centrais da vertente do Capitalismo Agrário são Mendras e Lamarche, os quais influenciaram teóricos contemporâneos brasileiros a partir da década de 1990 . Ambos afirmam que o crescimento do capitalismo na agricultura possibilitou a intensificação tecnológica, visando a potencialização da produção e defendem que o prognóstico do campesinato consistiria na sua interação ao mercado, no que seria substituído pelo agricultor familiar. Assim, para tais teóricos, não haveria motivo para o debate acerca das questões agrárias, já que o sistema capitalista seria suficiente para encontrar respostas para os possíveis impasses que surgiriam com o desenvolvimento do capitalismo na agricultura.

Utilizando o desenvolvimento agrário inglês como modelo teórico, Mendras (1984) proclamou a destruição do campesinato francês, após a segunda revolução agrícola. A civilização camponesa, segundo o autor, possui aspectos econômicos, sociais, políticos e culturais intercambiados de tal maneira que alterações ocorridas em qualquer um desses aspectos influenciam os demais, como um "jogo de cartas". Mendras (1976) aponta cinco características nucleares às sociedades camponesas, quais sejam: 1) autonomia (relativa) em relação à sociedade não-camponesa; 2) estrutura da organização do trabalho fundada na família; 3) organização econômica com uma lógica de independência relativa em relação aos mercados e ao Estado; 4) sociedade de conhecimentos compartilhados; e 5) função central dos mediadores entre a sociedade camponesa e a sociedade globalizada.

Lamarche (1993) apresenta uma teoria construída sobre as bases de um certo evolucionismo histórico, em que o modelo selvagem do campesinato seria paulatinamente substituído pelo modelo ideal, do agricultor familiar, mediante graus distintos, segundo uma maior ou menor integração ao mercado, sendo o camponês típico, aquele que produz para sua própria subsistência e de sua família, em uma escala, e o agricultor familiar na outra ponta, o que produz de acordo com a lógica do capital (p. 13-33). Teorias baseadas no paradigma do Capitalismo Agrário, frequentemente, associam o campesinato ao atraso e à bestialidade, preconceito cuja origem remonta do século XIII.

Abramovay (2012, p. 127) entende que o caráter camponês da organização social desaparece nas hipóteses em que o produtor agrário se insere no mercado, devendo produzir apenas para o consumo próprio e de sua família. Há, em sua ótica, uma incompatibilidade entre sociedades camponesas e ambiente econômico no qual prepondere relações especificamente mercantis. O camponês não pode direcionar a produção de acordo com as regras da oferta e da procura, mas concentrá-la tão somente nos estritos limites das necessidades da família. Caso isso ocorra, leva consigo o "próprio caráter burguês da organização social". O autor reconhece, todavia, que tais camponeses estão sujeitos a monopólios na compra e venda de seus produtos, em razão da precariedade nas comunicações, transportes e informações, sendo uma de suas principais características 
(2012, p. 128). Em sua teoria, a peculiaridade das sociedades camponesas é a "integração parcial a mercados incompletos". O caráter de integração apenas parcial decorreria de dois aspectos: a) o camponês escolhe seu produto pela sua flexibilidade, ou seja, pela possibilidade de alternar consumo e mercado, o que explicaria o plantio de alimentos não rentáveis, como é o caso da mandioca, produto bastante consumido e de fácil estocagem; b) parte de sua produção é destinada para sua subsistência e não para a venda.

Como observa Paulino (2012, p. 65), na teoria de Abramovay há uma proposta de substituição, quase automática, do termo campesinato por agricultura familiar, afastando todas as demais particularidades que caracterizam o camponês, privilegiando o mercado como elemento sobre o qual se baseiam a sociedade e as classes, em uma aproximação com concepções leninistas e afastamento da teoria marxista. Nessa ótica, as sociedades camponesas possuem uma natureza incompleta em sua racionalidade econômica, em razão de a racionalidade fundamentar-se nos vínculos de natureza pessoal, em relacionamento comunitário localizado e particularidade extra econômica das relações sociais de interdependência, além da organização familiar da divisão do trabalho. Há, portanto, segundo o autor, uma diferença social entre o produtor familiar e o campesinato: "O ambiente no qual se desenvolve a agricultura familiar contemporânea é exatamente aquele que vai asfixiar o camponês, obrigá-lo a se despojar de suas características constitutivas, minar as bases objetivas e simbólicas de sua reprodução social (ABRAMOVAY, 2012, p. 142). Vale observar, no particular, que Abramovay se alinha ao pensamento de Kautsky ao afirmar que não há campesinato quando existir inserção no mercado. Abramovay afasta, ainda, a possibilidade de haver qualquer produção de capital fundada em relações camponesas.

Paulino (2012, p. 56) discorda de Abramovay, por entender que tal limitação no conceito de campesinato importaria em uma redução na sua identificação por considerar os camponeses como "seres alheios, alienígenas, produzindo apenas para si e sua família, como se fossem refratários às influências do modo de produção do qual fazem parte". Em sua visão, no emolduramento do campesinato em contornos restritos, como meros trabalhadores familiares, está implícita uma estratégia política de banimento do conceito conquanto uma classe social. Com efeito, a oposição de Paulino está alinhada à teoria chayanoviana, segundo a qual não haveria qualquer incompatibilidade entre o planejamento dos cultivos camponeses com base no mercado. Chayanov (1974, p. 152) afirma que a organização do cultivo nas unidades de produção camponesas deve selecionar cultivos, observando: a) proporção de maior retorno, considerando não apenas as espécies mais valorizadas pelo mercado, mas também aquelas que possibilitem cobrir as necessidades de consumo da família; b) sua viabilidade econômica, atentando aos custos de circulação e transporte das mercadorias; gastos fixos com a compra e venda de mercadorias; c) devem 
ser combinados os cultivos de forma a não haver o esgotamento do índice de fertilidade do solo; d) a determinação do tamanho da área cultivada deve ser equivalente aos limites da força de trabalho disponível.

No entendimento de Abramovay (2012), a permanência do campesinato ou a sua aniquilação é um fenômeno conjuntural que requer uma alteração na estrutura socioeconômica ditada pelo avanço do capitalismo. Isso porque, em algum momento, o capital engendra relações comerciais que dilapidam toda forma de vida não integrada ao capitalismo. Assim, o campesinato, não sendo uma relação de trabalho profissional, é dragado pelo desenvolvimento do capitalismo e, para resistir, acaba por se transformar em agricultor familiar. No paradigma do Capitalismo Agrário de Abramovay, o camponês se integra à nova realidade em processo de desenvolvimento. Como a integração é um requisito para a continuidade, a resistência não faz sentido.

De acordo com José Eli da Veiga (2012, p. 32), a transição da agricultura feudal da Europa para a moderna pode ser resumida em três modelos, resultados das diferenças entre o embate de nobres e camponeses e do período em que ocorreu a limitação dos territórios: o inglês, o do Leste e o do Oeste. A decomposição do feudalismo, na Inglaterra, gerou três tipos de agricultores: proprietários fundiários rentistas, arrendatários-patrões e trabalhadores assalariados. Em sua análise, o desenvolvimento da agricultura moderna, nos séculos XVIII e XIX, em razão do advento dos avanços tecnológicos, sociais e econômicos possibilitaram a expansão do capitalismo, observando os três padrões básicos supracitados. A agricultura familiar, em sua tese, deve ser favorecida e integrada ao mercado, que impulsionará o desenvolvimento do capitalismo (FELíCIO, 2011).

Para José Graziano da Silva (1981, p. 45), o campesinato é parte da estrutura capitalista, pois o sistema sempre consegue encontrar meios de alcançar a produção do campo sobejante. Em relação à expansão do capitalismo no campo, Silva (1985, p. 40) defende que o capital privilegia algumas culturas, regiões e tipos específicos de médias e grandes unidades produtivas. Para ele, não haveria outro caminho ao camponês além do de aceitar as regras do mercado. E é precisamente a maior ou menor eficácia da política tecnológica que determinará se o campesinato terá um prognóstico direcionado ao proletariado ou à transformação em empresa capitalista (SILVA, 1999, p. 45, 137-138).

Schneider (2003) reconhece a posição de destaque da agricultura familiar e destaca as suas modificações, passando o cultivo da terra a ser cada vez mais concebido em apenas uma de duas dimensões. Trata-se da pluriatividade - uma forma de organização do trabalho em expansão, quando um ou mais membros da família passam a exercer atividades fora do contexto agrícola, seja no interior ou no exterior das propriedades. São atividades econômicas e produtivas, ligadas ou não à agricultura ou ao cultivo da terra. $\mathrm{A}$ pluriatividade é, segundo o autor, uma importante estratégia de reprodução social e 
econômica das famílias do campo. Até mesmo o camponês, enquanto sujeito, é reduzido a um produto do capital, ao ser introduzido na paisagem turística do campo, conquanto produto: "o trabalhador com chapéu de palha que retira leite da vaca, que colhe as verduras etc.; proletarizado nos empreendimentos turísticos" (BASSETTI, 2009, p. 4).

\section{Autores dos dois paradigmas}

José de Souza Martins (2010) e Maria de Nazareth Baudel Wanderley (2014) foram incluídos em um terceiro grupo, o dos autores que, em algum momento, mudaram a estrutura de seu trabalho, de forma a migrar de um paradigma a outro. Como observa Felício (2011), as teses centrais do paradigma da Questão Agrária estão presentes nos dois primeiros períodos dos estudos de Martins. A partir do terceiro período de sua obra, Martins passa a defender as ideias nucleares ao paradigma do Capitalismo Agrário. Já na obra de Wanderley, o caminho é inverso: os fundamentos teóricos do paradigma do Capitalismo Agrário encontram-se no segundo período e no terceiro, as teses do paradigma da Questão Agrária estão perceptíveis. No livro Os camponeses e a política no Brasil, publicado em 1981, Martins percorre a trajetória do campesinato brasileiro na história política desde o fim da escravidão, em 1888, até o golpe militar de 1964, e demonstra que o campesinato é a única classe social que, desde a proclamação da República, posiciona-se contrariamente ao Exército, em um protagonismo na luta contra o capital. Ele entende que o campesinato mantém uma posição de resistência, ao sustentar sua identidade, mediante a luta revolucionária, ideias contidas no paradigma da Questão Agrária.

Os princípios basilares de seus trabalhos adquirem uma nova feição e Martins (2000) passa negar a posição de protagonista do campesinato, considerando-o um segmento reacionário que "nunca teve, em consequência da escravidão, um campesinato livre significativamente capaz de defender os próprios direitos" (MARTINS, 2000, p. 142). Defende, o citado autor, que a função do campesinato no desenvolvimento da industrialização da agricultura foi secundária e que, para subsistir, o campesinato deverá integrar-se ao mercado, aderir aos avanços tecnológicos e maximizar sua produção, teses defendidas pelo paradigma do Capitalismo Agrário.

Nos estudos de Maria de Nazareth Baudel Wanderley (2014), o conceito de campesinato no Brasil ainda é tema controvertido, ponto central de disputas políticas, pois o que está em jogo é a posição social desses agricultores. A autonomia dos agricultores familiares tem sido reafirmada, compreendendo-os como sujeitos dotados de uma experiência com a terra, a qual os possibilita assumir posição de destaque no progresso do meio rural brasileiro. Trata-se de um conjunto heterogêneo de agricultores não patronais e não latifundiários que possuem sua forma peculiar de viver e trabalhar, com múltiplas identidades e distintas relações com a cidade, com o mercado e com o Estado. E é a presença da heterogeneidade que marca o campesinato, "para além das particularidades de 
cada situação e da conexão (ou superposição) das múltiplas referências identitárias, assumindo que os conceitos de campesinato e agricultura familiar podem ser compreendidos como equivalentes" (WANDERLEY, 2014, p. 7). Para ela, o campesinato é historicamente predominante nas sociedades tradicionais e se constitui de grupos sociais que estão em transição entre a tribo primitiva e a sociedade industrial (FELÍCIO, 2011).

O tema pertinente à questão agrária tem em seu núcleo o ponto de atrito no embate entre o capital e o campesinato, suas lógicas são distintas. O capitalismo sobrevive e depende da ocupação de novos territórios, pela expansão de seu "Império", com crescente e insaciável acumulação de riquezas, em um ritmo frenético. A lógica camponesa é distinta. $\mathrm{O}$ camponês mantém o controle sobre o seu trabalho, sobre os meios de produção, sobre seu tempo, obedecendo as estações do ano. O valor não é a renda, mas a terra. Não é a acumulação, mas a sua autonomia, sua liberdade, comparecendo no mundo sem viver a alienação do trabalho.

\section{Campesinato - conceito político}

As dificuldades na contextualização dos aspectos teóricos da questão agrária e na definição do conceito de campesinato no contexto brasileiro não são poucas, uma vez que a nossa estrutura fundiária encontra-se inserida em um contexto histórico-social amplo, construído a partir de tempos históricos circulares que remontam ao início da construção do território brasileiro, em seu período colonial, processo cujos contornos foram e são definidos de acordo com o inter-relacionamento das classes e categorias sociais. Antes mesmo da chegada dos imigrantes europeus em áreas estratégicas e de fronteiras, a classe camponesa estava em um período gestacional, marcado por um complexo processo de expropriação e espoliação de um grupo de trabalhadores depauperados que viviam em uma espécie de território paralelo à grande propriedade: os agregados, brancos e mestiços, indivíduos do mundo rural, desprovidos dos meios de produção, sem uma função específica na ordem produtiva (GUIMARÃES, 2009, p. 44). É possível perceber a disputa entre os modelos paradigmáticos apontados no tópico anterior, na luta pelo acesso à terra, desde o primeiro dia em que os europeus pisaram a Terra Brasilis.

A concepção segundo a qual o surgimento da pequena propriedade no Brasil se deu a partir da colonização europeia no século XIX, pela dádiva de grupos políticos que procuravam apenas a colonização do solo brasileiro, se apresenta como uma amnésia, uma negação da posição de resistência histórica da classe camponesa. A figura do brasileiro nativo "indolente" ou "incapaz" para o trabalho tem um sentido prático: "apagar da história a longa e obstinada batalha que os elementos geradores da classe camponesa tiveram de travar contra os seus inimigos, até emergirem definitivamente na vida rural brasileira" (GUIMARÃES, 2009, p. 48). 
A par da complexidade da questão agrária do Brasil, e talvez por esta razão, outra dificuldade comumente apresentada para a sedimentação de uma posição política marcada pela luta ao acesso à terra é a ausência de identificação dos próprios indivíduos como classe camponesa. Como muito bem lembra Paulino (2012, p. 29), antes de dizer que são camponeses (se é que o fazem), apresentam-se como agricultores, lavradores, boias-frias, parceiros, meeiros ou sitiantes. A ausência de autoidentificação conquanto classe não impede o seu reconhecimento, marcado pelo próprio controle sobre os meios de produção e sobre o próprio trabalho. Essa aversão ao uso do termo, pelos próprios agentes, é facilmente explicada em razão do curso da história no Brasil, ao associar os camponeses ao atraso e à selvageria, "evidentemente pela óptica dos que conservaram por séculos o poder dos registros escritos, que são os que efetivamente entram para a história" (PAULINO, 2012, p. 30). O significado de campesinato, portanto, é um impasse muito mais político que conceitual, objeto de um intenso debate e de disputas travadas na arena política, envolvendo diversos movimentos sociais, pesquisadores acadêmicos e agentes formuladores de políticas públicas, dentre outros.

Segundo Wanderley (2014), o campesinato possui dupla conotação. Para alguns, corresponderia "às formas mais tradicionais da agricultura, realizadas em pequena escala, dispondo de parcos recursos produtivos, pouco integrado ao mercado e à vida urbana e frequentemente identificado à incivilidade e ao atraso econômico e social". Seria, nesse caso, figura distinta da agricultura familiar, pelo fato de essa modalidade estar mais integrada às cidades e aos mercados, muito embora possuam, ambas, condições de produção restritas. Para outro grupo, a palavra campesinato possui forte conteúdo político pela sua associação ao movimento camponês, considerado "subversivo" e, por esse motivo, foi fortemente perseguido pelos governos militares, no poder de 1964 a 1985. Assim, a busca de uma expressão mais aceita politicamente, levou, nesse período, à adoção oficial de expressões outras, com forte conteúdo depreciativo e impreciso, como "pequenos produtores", "agricultores de subsistência" e "produtores de baixa renda". Seyferth (2011), citando um estudo sobre as peculiaridades do campesinato latino-americano de Wolf, lembra o quão árdua é a tarefa de conceituar o sujeito camponês, uma vez que conceitos são instrumentos abstratos do pensamento e não verdades imutáveis.

A categoria "agricultura familiar" foi adotada pelo Estado brasileiro, nos anos 1990, com a formulação do Pronaf, um amplo programa de apoio à produção agrícola de base familiar. A partir de então o conteúdo histórico-político que a palavra "camponês" inspirava foi disperso, "ao mesmo tempo em que se afirmava, pela primeira vez, o reconhecimento da condição de produtor agrícola e uma valoração positiva de suas particularidades" (WANDERLEY, 2014). Os agricultores familiares integrantes das principais culturas agropecuárias do país, que participam das cadeias produtivas globalizadas, são incluídos na 
categoria genérica do "agronegócio", assim como os grandes empresários do setor agrícola do país.

O campesinato brasileiro foi impulsionado pela lógica capitalista, em um processo iniciado pela drástica desterritorialização dos povos nativos, mediante o etnocídio, genocídio e aculturação dos diferentes povos indígenas. Ao grupo dos aprisionados e coagidos, somam-se os escravos e em seguida, os europeus, excluídos do acordo pelo monopólio de classes instaurado no Brasil, unidos pela luta por liberdade e por terras onde possam trabalhar e viver em dignidade. A existência do campesinato, relação não-capitalista de produção, "representa, contraditoriamente, possibilidade de acumulação do capital fora do circuito produtivo tipicamente capitalista" (PAULINO, 2012, p. 43). Essa particularidade, longe de ser meramente teórica, é o fio condutor a compreender-se por qual motivo as culturas que formam os principais itens da alimentação básica da população brasileira são produzidas por agricultores familiares. A interpretação de que o camponês inserido no mercado capitalista e que utiliza modernas tecnologias não pode ser visto como pertencente a essa categoria, mas sim a uma categoria "superior", a de agricultor familiar, como uma espécie de ascensão social, é equivocada. Em verdade, "criou-se um novo nome para se falar do mesmo sujeito" (FERNANDES, 2007, p. 79). O camponês não é o agricultor pobre, que planta apenas para sua subsistência, vivendo em uma espécie de ilha, isolado do mundo capitalista. A oferta de produtos excedentes ao mercado e mesmo sua produção com vistas à venda, pelo camponês, não é, em si, um fato negativo ou positivo. É apenas um fato. Precisamente para esclarecer esse aspecto fundamental da temática agrária, ao valorar, de alguma forma, a maior ou menor inserção dos camponeses ao mercado, que gostaríamos de incorporar as reflexões de Paulino (2012, p.45) acerca da relação entre campesinato e capitalismo. Os fundamentos da acumulação ampliada do capital não são invertidos pela existência do campesinato. Ao revés, por estar assentado em relações não tipicamente capitalistas, é possível haver uma apropriação de sua renda pelos setores capitalistas em seu grau máximo. Isso porque ocorre a apropriação do excedente da renda gerada pelo camponês sob duas formas: a) direta, quando o capitalista realiza a intermediação entre os produtores e consumidores finais ao transportar, comercializar e armazenar os produtos e b) indireta, pois um montante menor de dinheiro, na forma de capital é despendido com o pagamento de salários na produção de alimentos, já que o custo da reprodução da força de trabalho do camponês é reduzido, na medida em que os trabalhadores, membros da família, não são remunerados pela extração do lucro médio. Por outro lado, a caracterização do campesinato não é prejudicada nas hipóteses de venda da força de trabalho, contanto que seja menos representativa que a do trabalho familiar autônomo.

Permitam-me tentar precisar ainda melhor essa ideia central para meu argumento

Geografia (Londrina) v. 26. no. 2. p. 58-77, jul/dez, 2017. 
neste ensaio. Esse sujeito social peculiar, o camponês, possui posição de protagonismo no que se refere à relevante e urgente temática das estratégias nacionais para assegurar alimentação à população, de forma permanente. Isso porque não é pelo caminho da importação que a segurança alimentar será garantida, como lembra Mazzei (2007), em razão, justamente, da insegurança que a dependência de produtos externos proporciona. As políticas de importação de grandes quantidades de alimentos a preços subsidiados possuem um efeito social nefasto e destruidor, ao levar os produtores locais à ruína, expulsando-os do campo. O caminho da segurança alimentar é o inverso: a promoção do homem do campo, mediante a proteção do acesso à terra, com apoio para transformá-la em área produtiva (ROSSET, 2003).

Chonchol (2005) enfatiza a necessidade de se debater temas como segurança alimentar e soberania alimentar, apresentando um forte enfrentamento ao modelo econômico do agronegócio. Essas duas esferas, do campesinato e do agronegócio, paralelas aos paradigmas da Questão Agrária e do Capitalismo Agrário, devem ser separadas analiticamente, uma vez que obedecem a lógicas distintas de desenvolvimento. Como lembra Souza (2009, p. 116-117), a teoria da soberania alimentar não nega a inserção dos agricultores ao mercado. Em vez disso, incentiva o planejamento e a efetivação de políticas que promovam o direito dos povos ao planejamento da produção de alimentos de forma saudável e ecologicamente sustentável. Ela considera que, historicamente, a protelação da realização da reforma agrária no Brasil e a escolha pelo modelo de transformação da terra em mercadoria, acabou por incentivar a saída do homem do campo, com a crescente concentração econômica em poucas empresas transnacionais, as quais passaram a deter o poder de fixar preços e condições no que diz respeito à produção de alimentos.

A concepção fatalista, segundo a qual a fome e a desnutrição seriam efeitos de catástrofes ou de eventos geográficos foi contestada por Souza (2009). A crise dos alimentos surge a partir da construção de obstáculos que excluem milhões de pessoas do acesso à terra e de instrumentos e insumos necessários à produção de alimentos. $O$ atingimento da soberania alimentar só será possível pela promoção de uma radical Reforma Agrária, com a promoção das agriculturas familiares.

Para além dos imaginários sociais de que em algum momento na história do Brasil ocorrerá a Reforma Agrária, diante da rapidez da desterritorialização da agricultura camponesa, do empobrecimento dos pequenos agricultores, a ocupação da terra apresentase como forma de ressocialização. O território, para o camponês, é um trunfo (FERNANDES, 2007). Cada ocupação de terra é uma batalha vencida na arena das disputas entre os territórios do capital e do campesinato. O camponês "pode se fortalecer cada vez mais se conseguir enfrentar e superar as ideologias e as estratégias do 
agronegócio", dentre as quais encontra-se justamente a imprecisão de sua identidade socioterritorial.

\section{CONSIDERAÇÕES FINAIS}

O camponês é o mesmo sujeito do agricultor familiar: uma organização econômica fundada no trabalho da família, ainda que possua algum grau de integração aos mercados e de tecnificação. A dificuldade é, efetivamente, traçar a linha divisória entre essa modalidade de relação de trabalho para aquela fundada sobre as bases de trabalho assalariado, construída como uma empresa capitalista. Essa passagem é cinzenta e não comporta uma análise exata de tais parâmetros. Um pressuposto implícito da manobra analítica que considera o campesinato uma forma arcaica de agricultura, na busca por se manter não apenas as premissas do "evolucionismo histórico", mencionado anteriormente, passa pela estratégia de menosprezar e diminuir o conteúdo político da categoria, associando-o a movimentos "subversivos". Uma grande parte dos teóricos que se detiveram no estudo do campesinato na América Latina estava, e ainda está, influenciada, explícita ou implicitamente, por essa pressuposição.

A maneira de compreender o homem da roça tem uma história de romantismo, expressada pelo Jeca Tatu de Monteiro Lobato. A partir da noção de "evolução humana", importada diretamente de construções teóricas produzidas nos países centrais, Lobato não produz, mas revela o argumento, alicerce de uma visão eugenista do autor, impregnada no ideário da sociedade brasileira. No contexto deste artigo, convém destacar a ideia do caipira associada ao homem que trabalha a terra com suas mãos, reproduzindo a indiferenciação, característica de teorias que associam raça, gênero e nação e defendem a oposição à vida simples como antídoto para os problemas dos indivíduos que possuem uma estreita relação com a terra.

Para o objetivo deste estudo, no entanto, o fundamental é enfatizar que essa ideologia subjacente ao discurso do capitalismo agrário possui interconexão com um componente implícito: o formato de alto grau de concentração fundiária, característica que remonta ao período da colonização europeia. E esse é o ponto central no debate da questão agrária no Brasil: o traçado sesmarial persiste.

\section{REFERÊNCIAS}

ABRAMOVAY, R. Paradigmas do capitalismo agrário em questão. 3. ed. São Paulo: Edusp, 2012.

ALVES, F. D. Importância das teorias agrárias para a geografia rural. Revista Mercator, Fortaleza, Vol. 8, n. 16, 2009.

BAIARDI A.; ALENCAR, M. M. A. Agricultura Familiar, seu Interesse Acadêmico, sua Lógica 
Constitutiva e sua Resiliência no Brasil. RESR, São Paulo, Vol. 52, Supl. 1, p. S045-S062, 2014.

BARTRA, A. Marginales, Polifônicos, Trashumantes: os campesinos del milênio.

BASSETTI, T. M. B. Turismo e campesinato - embates ideológicos e culturais em Colombo-PR. 2009. Tese (doutorado em Geografia Humana). Universidade de São Paulo: São Paulo, 2009.

BORSATTO S. B.; CARMO S. C. A construção do discurso agroecológico no Movimento dos Trabalhadores Rurais Sem-Terra. Revista de Economia e Sociologia Rural, Brasília, vol.51, n.4, dez, 2003. Disponível em: <http://dx.doi.org/10.1590/S0103$20032013000400002>$. Acesso em 17 jan. 2017.

CAMPOS, J. F. S. Leituras dos territórios paradigmáticos da Geografia Agrária: análise dos grupos de pesquisa do estado de São Paulo. 2012. 387 p. Tese (Doutorado em Geografia) - Universidade Estadual Paulista “Júlio Mesquita" (Unesp), Presidente Prudente.

CARNEIRO, P. A S. A unidade de produção familiar e os enfoques teóricos clássicos. 2009. Campo-território. Revista de geografia agrária, v.4, n. 8, p. 52-66, ago. 2009.

CHAYANOV, A. V. La Organización de La Unidad Econômica Campesina. Buenos Aires: Ediciones Nueva Vision, 1974.

FELÍCIO, M. J. Contribuição ao debate paradigmático da questão agrária e do capitalismo agrário. Tese de Doutorado apresentada ao Programa de Pós-Graduação em Geografia da FCT UNESP. 2011.

FERNANDES, B. M. Territórios da questão agrária: campesinato, reforma agrária e agronegócio. Revista da Associação Brasileira de Reforma Agrária - ABRA. v. 34, N 2 • JUL / DEZ - 2007, p. 76-93.

FERNANDES, B.F.; MARQUES, M.I.M, SUZUKI, J.C. (orgs.). In: Geografia Agrária Teoria e poder. São Paulo: Expressão Popular, 2007, p. 85-103.

GUIMARÃES, A. P. VI Formação da pequena propriedade: I. Intrusos e posseiros. In: Quatro séculos de latifúndio. Camponeses brasileiros Leituras e interpretações clássicas, volume 1. In: In: WELCH, Clifford A; MALAGODI, Edgard; CAVALCANTI, Josefa S. B; WANDERLEY, M. N. et al. (Orgs.). Camponeses Brasileiros: Leituras e interpretações clássicas. São Paulo/Brasília: UNESP/NEAD, 2009. 335p.

KAUTSKY, K. A questão agrária. São Paulo: Proposta Editorial, 3. ed., 1980.

KUHN, T. S. A estrutura das revoluções científicas. 2. ed. São Paulo: Perspectiva, 1978.

LAMARCHE, H. Agricultura familiar. Campinas: Editora da UNICAMP, 1993.

LENIN, V. I. O desenvolvimento do Capitalismo na Rússia: O processo de formação do Mercado Interno para a Grande Indústria. São Paulo: Nova Cultural, 1985.

LUXEMBURG, R. A Acumulação do Capital. São Paulo: Nova Cultura, 1985.

MARTINS, J. S. A sujeição da renda da terra ao capital. Encontros com a civilização brasileira, 22. Rio de Janeiro: Civilização Brasileira. 1980.

Reforma Agrária O impossível Diálogo. São Paulo: Edusp, 2000.

O cativeiro da terra. São Paulo: Hucitec, 2010.

Os camponeses e a política no Brasil. 5. ed. Petrópolis: Vozes, 1995.

MARX, K. O capital: crítica da economia política. São Paulo: Boitempo, 2013.

O Dezoito Brumário de Luis Bonaparte. São Paulo: Centauro, 2011.

MARX, K; ENGELS F., A ideologia alemã. Martins Fontes. São Paulo: 2001.

Geografia (Londrina) v. 26. no. 2. p. $58-77$, jul/dez, 2017.

ISSN 2447-1747 
MENDONÇA, A. L.O. O legado de Thomas Kuhn após cinquenta anos. Disponível em: $<$ http:// www.scielo.br/scielophp? Script=sci_artlextEpid=S3166201200300006 >. Acesso em: 17 jan. 2017.

MENDRAS, H, Sociedades camponesas. Rio de Janeiro: Zahar Editores, 1976.

La Fin des paysans. Paris: Actes Sud, 1984.

NETTO, José Paulo (Org.). Lênin: o desenvolvimento do capitalismo na Rússia. São Paulo: Nova Cultural, 1985.

PAULINO, E. T., Por uma geografia dos camponeses. São Paulo: UNESP, 2012.

PAULINO, E. T.; FABRINI, J. E. (Orgs.). Campesinato e territórios em disputa. São Paulo: Expressão Popular, 2008.

PLOEG, J. D. V. D. Camponeses e Impérios Alimentares Lutas por Autonomia e

Sustentabilidade na Era da Globalização. Porto Alegre: UFRGS Editora, 2008.

SABOURIN, E., Teoria da Reciprocidade e sócio-antropologia do desenvolvimento, 2011.

Sociologias, Porto Alegre, ano 13, no 27, mai./ago. 2011, p. 24-51.

SANTOS, C. R.S., Territórios não-capitalistas e reprodução do capital: o papel de Rosa Luxemburgo. Revista Mercator, v. 9, n. 18, jan./abr, p. 27-38, 2010.

SCHNEIDER, S. A pluriatividade na agricultura familiar. Porto Alegre: Editora da UFRGS, 2003.

SEYFERTH, G. Campesinato e o estado no Brasil. Revista Mana, Rio de Janeiro, n. 17, p. 395-417, 2011. Disponível em:

<http://www.scielo.br/scielo.php?script=sci_arttext\&pid=S0104-93132011000200006>.

Acesso em: 17 jan. 2017.

SHANIN, T. La classe Incomoda. Alianza Editorial: Madrid, 1983.

SILVA, J. G. A modernização dolorosa Estrutura agrária, fronteira agrícola e trabalhadores rurais no Brasil, São Paulo: Zahar, 1981.

O Novo Rural Brasileiro. Campinas: Unicamp, 1999.

SOUZA, A. S. Um debate acerca da soberania alimentar e da agroecologia: um desafio de percepção e de prática. Ou, de que lado é o meu quintal? Revista Pegada, vol. 10, n.1, jun. /2009. Disponível em:

$<$ http://revista.fct.unesp.br/index.php/pegada/article/viewFile/1682/1617>. Acesso em: 17 jan. 2017.

VEIGA, J. E. da. O desenvolvimento agrícola: uma visão histórica. São Paulo: Edusp, 2012.

WANDERLEY, M. N. B. O campesinato brasileiro: uma história de resistência. Rev. Econ, Sociol. Rural, Brasília, vol. 52. supl. 1., 2014.

\footnotetext{
${ }^{1}$ Mestranda no Programa de Pós-graduação em Direitos e Garantias Fundamentais da Faculdade de Direito de Vitória (FDV); Graduada em Direito pela Universidade Federal do Espírito Santo; Juíza Substituta do Trabalho do Tribunal Regional do Trabalho da 17 $7^{\text {a }}$ Região. Endereço: Rua Desembargador João Manoel de Carvalho, no 190, ap. 301, Barro Vermelho, Vitória-ES. CEP: 29057630. Email: rosalystange@terra.com.br.

${ }^{2}$ Doutor em Ciências Humanas pelo Programa de Pós-graduação em Sociologia e Antropologia da Universidade Federal do Rio de Janeiro (UFRJ). Atualmente é professor/pesquisador do Programa de Pós-graduação Stricto Sensu em Direitos e Garantias Fundamentais da Faculdade de Direito de Vitória (FDV). E-mail: afprsantos@gmail.com.
} 